\title{
18. Muntlig interaktion i det virtuella klassrummet - möjligheter och utmaningar
}

\section{Monika Stridfeldt}

\subsection{Inledning}

Nätbaserad utbildning har utvecklats på senare år och erbjuds nu vid fler lärosäten än tidigare. Det finns all anledning att tro att den är en del av framtiden. Till skillnad från traditionella distanskurser där deltagarna har lite eller ingen kontakt med varandra, går utvecklingen mot nätbaserade kurser där deltagarna har möjlighet att interagera i realtid med varandra och med läraren via synkrona onlineseminarier.

Den första terminen i svenska högskoleutbildningar i franska och andra romanska språk brukar innehålla en delkurs i muntlig språkfärdighet, som går ut på att studenterna ska öva sin muntliga förmåga genom att kommunicera muntligt med varandra. I dessa kurser brukar även ingå fonetikstudier och uttalsträning i någon form. En fråga man då kan ställa sig är hur sådana kurser kan genomföras när inte lärare och deltagare träffas fysiskt. Jag kommer i den här artikeln att presentera och diskutera egna och andras erfarenheter och reflektioner kring möjligheter och utmaningar när det gäller muntlig interaktion i det virtuella klassrummet.

\subsection{Muntlig språkfärdighet i det virtuella klassrummet}

Muntlig språkfärdighet är ett komplext fenomen och består av en mängd olika kunskaper och färdigheter, såsom kunskaper i vokabulär, uttal och grammatik, men även sociala färdigheter och förmåga att interagera med andra människor. I kursplanen för kursen "Franska: Muntlig språkfärdighet" vid Högskolan Dalarna står att "kursen syftar till att utveckla färdigheter i att kommunicera muntligt på franska”. Ett av kursens mål är att studenterna efter avslutad kurs ska kunna kommunicera muntligt i vardagliga sammanhang med ett godtagbart uttal. Ett annat mål är att de ska kunna förstå vårdat franskt talspråk. Eftersom muntlig språkfärdighet inte bara innefattar att kunna uttrycka sig på språket i fråga utan även att kunna lyssna på och interagera med andra som talar språket, är det viktigt att studenterna får 
träna på just detta. Då vår kurs i muntlig språkfärdighet är helt nätbaserad utan någon fysisk träff, är seminarierna i realtid den möjlighet studenterna har att inom ramen för kursen interagera muntligt med andra studenter och med läraren.

Undervisning på högskolenivå innehåller traditionellt föreläsningar och seminarier. I vår nätbaserade undervisning ges dessa föreläsningar och seminarier digitalt. Kursens virtuella klassrum består dels av lärplattformen och dess innehåll, dels av samtalsrummet som vi träffas i för seminarierna. Lärplattformen utgör kursens bas och innehåller schema och annan information, inspelade föreläsningar, dokument, övningar, diskussionsforum, länkar till externa webbsidor m.m. Här lämnar studenterna även in inlämningsuppgifter och gör onlineprov. Föreläsningarna är inspelade och ligger på lärplattformen, där studenterna kan lyssna och titta på dem oberoende av tid och rum, medan seminarierna sker online i realtid och alltså är oberoende av rum men inte av tid. Detta är en form av flexibelt lärande i och med att studenterna kan välja plats för studierna och i viss mån även tid. Bian (2009) menar att synkrona och asynkrona media kompletterar varandra i nätbaserad utbildning. Cunningham, Beers Fägersten \& Holmsten (2010: 162) poängterar att synkrona och asynkrona media främjar olika inlärningsstilar. De synkrona mötena som kännetecknas av spontan och improviserad kommunikation passar kanske bättre för mer självsäkra studenter, medan svagare och mer försiktiga studenter kanske föredrar asynkrona kommunikationskanaler som ger mer tid till att tänka och formulera sig. I vårt upplägg med inspelade föreläsningar kan de studenter som är i behov av det lyssna flera gånger på föreläsningarna för att förbereda sig inför de synkrona seminarierna där de ska interagera med andra kursdeltagare. Under kursens gång lämnar studenterna även in ett antal inspelningar, där de får chansen att använda sin muntliga språkfärdighet i en asynkron kanal.

Vi använder oss av det så kallade omvända eller flippade klassrummet (se t.ex. Barker 2013). Studenterna förväntas lyssna på inspelade föreläsningar och göra övningar på egen hand innan seminariet, vilket ger mer tid till frågor, gruppövningar och diskussioner när vi träffas. Mycket av seminarietiden ägnas därför åt studentaktivitet - det är studenternas egen aktivitet och lärande som är i fokus. Vi ger stort utrymme åt samtal och övningar i grupp, och ansluter oss därmed utbildningsfilosofiskt till bl.a. Vygotskys 
(1978) och Säljös (2000) sociokulturella perspektiv på lärande, där man ser elevens eller studentens lärande i samspel och kommunikation med andra som centralt. Flippat klassrum brukar ofta innebära en kombination av datorbaserade aktiviteter och fysiska klassrumsträffar, men i vårt fall sker allt via datorn.

Kontinuiteten är viktig. Examinationen sker kontinuerligt genom bedömning av studenternas prestation på seminarierna och genom muntliga inlämningsuppgifter i form av inspelningar, skriftliga fonetikuppgifter, skriftliga forumdiskussioner samt ett avslutande muntligt prov som sker online.

Våra nätbaserade seminarier sker synkront med hjälp av programvaran Adobe Connect, som högskolans tekniska support har anpassat för våra behov. Lärare och studenter loggar in i ett samtalsrum och kan på detta sätt träffas i ett virtuellt klassrum där man kan se och samtala med varandra $\mathrm{i}$ realtid med hjälp av webbkamera, mikrofon och hörlurar.

I studenternas scheman står vilken tid och i vilket samtalsrum seminarierna äger rum. Seminarierna är obligatoriska och studenterna ska delta aktivt. I samtalsrummet kan läraren visa olika typer av texter och bilder på en whiteboardtavla, även skannade dokument. Man kan också ladda upp ljudfiler, filmer, Youtube-klipp m.m. som alla seminariedeltagare kan se och höra. Det finns ett fönster med textchattfunktion som används av både studenter och lärare och det finns också ett fönster för anteckningar. Whiteboardtavlan kan även användas till att rita och skriva på, av både lärare och studenter.

Alla inloggade deltagare i rummet syns i form av en namnlista. När deltagarna slår på sina webbkameror syns deras bilder i ett fönster. Studenterna kan välja att ha sin mikrofon på- eller avslagen. Är man många personer i helklass brukar det fungera bäst om bara den som talar för tillfället har sin mikrofon påslagen, men i mindre grupper blir samtalen naturligare om alla har sina mikrofoner påslagna hela tiden. Den som talar får en liten mikrofonsymbol vid sitt namn och även en blå ram runt sin kamerabild, vilket gör det lättare att se vem som talar, även om man så småningom lär sig känna igen studenternas röster. Studenterna kan räcka upp handen genom att klicka på en ikon som föreställer en person som räcker upp handen och då syns denna symbol vid studentens namn. Förutom att räcka upp handen 
kan man genom olika symboler ge respons på vad som sägs, t.ex. med en applådsymbol eller en smiley.

När studenterna loggar in i det virtuella seminarierummet förväntas de ha tagit del av inspelade föreläsningar och andra dokument på lärplattformen. Det är alltså meningen att de ska komma väl förberedda till seminariet så att de kan delta i övningar och diskussioner och därmed har de bättre förutsättningar att ställa relevanta frågor. Eftersom seminariet är examinerande är det ur rättssäkerhetssynpunkt viktigt att studenterna slår på sin webbkamera så att det är lättare att identifiera dem. Att kunna se varandra är naturligtvis också en fördel då det handlar om en muntlig kurs där även kroppsspråket spelar in.

Läraren kan dela in studenterna i mindre grupper, så kallade Breakout rooms, vilket är lämpligt för diskussioner och andra övningar. Det går att välja antalet grupper och sedan fördela studenterna manuellt eller slumpmässigt i dessa grupper. Läraren kan sedan förflytta sig mellan grupperna. När gruppövningen är klar kan läraren snabbt återsamla alla deltagare i huvudrummet. Det brukar ofta vara lagom med fyra studenter per grupp, men vid vissa övningar passar det bättre att studenterna arbetar två och två. En fördel med små grupper är förstås att alla studenter då deltar mer aktivt och får chans att prata mer. Liksom i det vanliga klassrummet uppstår problemet att vissa studenter pratar mycket medan andra sitter tysta. Som Messina Dahlberg (2015) påpekar, blir det en helt annan dynamik när studenterna jobbar i mindre grupper. De måste då "vara närvarande” på ett annat sätt. Jag upplever själv att tysta och passiva studenter kan passera mer obemärkt i det nätbaserade klassrummet än i det traditionella klassrummet, men detta gäller bara i helklass när det är många studenter. När studenterna arbetar i små grupper märks det mycket tydligt om någon inte deltar aktivt. Ytterligare en fördel med små grupper är att studenterna då kan ha sina mikrofoner påslagna hela tiden, vilket skapar naturligare samtal. Som Högberg (2015: 169) konstaterar, kan nätbaserade seminarier lätt få en monologisk karaktär på grund av avsaknaden av ett utbyte av blickar och övrigt kroppsspråk, vilket gör det svårt att veta hur det man säger tas emot av de andra. En konsekvens av detta är att studenter då ofta låter varandra tala till punkt och väntar på sin tur i samtalet. Högberg påpekar att det är vanligt att studenter på något sätt markerar att de talat klart. Högberg 
tillägger dock att det är lättare att överblicka varandras närvaro i mindre samtalsgrupper om tre till fyra personer och att det också är av betydelse att deltagarna då i högre utsträckning har sina mikrofoner påslagna hela tiden. Om alla dessutom har sin webbkamera påslagen förbättras överblicken av de andras närvaro ytterligare.

I grupprummen samtalar studenterna och gör övningar tillsammans. Läraren laddar upp ett dokument med övningen, som alla kan se på sin skärm. Det går att skriva på whiteboardtavlan, alltså på det uppladdade dokumentet, men det är enklare att skriva i chatten eller i anteckningsfönstret. En övning i vår kurs i muntlig språkfärdighet kan exempelvis gå till så att studenterna ska försöka tyda meningar som är skrivna i fonetisk skrift och skriva dem med vanliga bokstäver i chattfönstret. De ska göra övningen tillsammans och diskutera sina lösningar med varandra. En annan övning kan vara att studenterna i tur och ordning ska uttala ett ord som innehåller antingen det tonlösa /s/ eller det tonande /z/. De ser då framför sig på skärmen en lista med minimala par av typen poisson - poison, ils sont - ils ont, deux sours deux heures etc. En student uttalar antingen poisson eller poison och de andra studenterna ska lyssna och säga vilket av orden studenten uttalade. Detta är vanliga övningar som man brukar göra i traditionella klassrum men som fungerar bra även i det nätbaserade klassrummet, trots att ljudkvaliteten ofta är sämre än i det vanliga klassrummet.

Läraren förflyttar sig mellan de olika grupprummen men kan bara besöka ett rum i taget och kan bara höra vad som sägs i ett grupprum i taget. Detta är en skillnad jämfört med ett traditionellt klassrum där studenterna sitter utspridda i grupper i klassrummet och läraren har överblick över alla samtidigt, men det liknar den situation då studenterna lämnar det traditionella klassrummet och går iväg för att arbeta i mindre grupper i olika rum. Studenterna i det nätbaserade seminariet kan dock skicka ett meddelande till läraren om att de t.ex. är klara med uppgiften. När gruppövningen är klar flyttar läraren tillbaka alla till huvudrummet igen för att gå igenom övningen tillsammans och kanske diskutera vad som sagts i de små grupperna. Därefter kan man fortsätta med en kort genomgång av något annat moment eller skicka ut studenterna i grupperna igen för att göra ytterligare en övning.

I en kurs i muntlig språkfärdighet är det naturligtvis viktigt att studenterna får träning i att samtala och diskutera. Ett sätt att göra detta i det virtuella 
klassrummet är att studenterna innan seminariet tar del av något material som de sedan diskuterar med varandra när de träffas, hellre ett muntligt dokument än en skriftlig text eftersom det handlar om en kurs i muntlig färdighet, och det blir då samtidigt en hörförståelseövning. Exempelvis ska studenterna inför ett av våra seminarier titta på en fransk dokumentär om Sverige, "Echappées belles : Suède", som finns fritt tillgänglig på Youtube. Dokumentären är ca 45 minuter lång och studenterna uppmanas att helst se den ett par gånger. Seminariet ägnas åt att i små grupper diskutera dokumentären. Studenterna har själva föreberett några diskussionsfrågor var utifrån aspekter som de fann särskilt intressanta och som de vill diskutera med de andra. Läraren laddar också upp några extra diskussionsfrågor under seminariet. Diskussionerna brukar bli mycket intressanta, inte minst tack vare att deltagarna har varierande bakgrund och ålder och att de sitter geografiskt utspridda, inte bara i Sverige utan över hela världen.

\subsection{Att skapa en gynnsam lärmiljö}

Eftersom deltagarna i det nätbaserade seminariet inte träffas fysiskt är det mycket viktigt att ändå försöka skapa en gruppkänsla, något som enligt många studier är gynnsamt för motivationen och lärandet. Att skapa en stödjande och trivsam lärmiljö är givetvis viktigt oavsett om det gäller campus- eller distansundervisning, men det är möjligtvis ännu viktigare i distansundervisning. Saito \& Hayakawa Thor (2012: 212) citerar ett inlägg från en student som berättar om dåliga erfarenheter från en distanskurs vid ett annat lärosäte där en strikt undervisningsstil tillämpades. Studenten skriver:

I sometimes wished that my webcam would go kaput so at least I could hide my face. /.../ So, with a very strict teaching style, maybe distance learning is not the best option, because then you invite a very stressful moment into your house. To have a stressful class in a reality classroom, then at least you can go home and leave it all behind.

Om undervisningssituationen känns obehaglig kan det alltså kännas ännu värre om den äger rum i ens eget hem. I ett riktigt klassrum kan man, så som studenten uttrycker det, åtminstone lämna det hela bakom sig när man går hem, men när man bjudit in undervisningen i sitt eget hem är det inte lika lätt. I nätbaserade kurser borde därför stor vikt läggas vid att 
skapa en trevlig stämning och ett positivt och tryggt inlärningsklimat. Saito \& Hayakawa Thor (2012) berättar att i syfte att skapa gruppkänsla och ett gynnsamt inlärningsklimat använder sig flera lärare i japanska vid Högskolan Dalarna av en metod som kallas "personalization" (Kawaguchi 2004) i sina nätbaserade kurser. Denna metod syftar till att få studenterna att uttrycka sina egna idéer, åsikter och känslor. Man drar nytta av att det finns ett naturligt "informationsgap" mellan studenter i en nätbaserad kurs, dvs. att de inte vet så mycket om varandra eftersom de läser kursen hemifrån. Saito \& Hayakawa Thor (2012: 213-214) redogör för en studie där de observerat hur ca 70 studenter på en nätbaserad kurs i japanska, muntlig språkfärdighet interagerade med varandra och hur de lärde sig japanska genom personalization-metoden. Resultaten visade att personalization är en effektiv pedagogisk metod för en interaktiv språkinlärning. Genom att exempelvis låta studenterna berätta om saker de har hemma (t.ex. varför de har sakerna, vad de används till och varför de är viktiga) och visa upp dem i webbkameran, blir studenterna motiverade att uttrycka sig på japanska. Detta gör kommunikationen meningsfull och ökar studenternas intresse att lära sig nya ord. Dessutom, när studenterna lär känna varandra, blir det lättare att skapa en gynnsam lärmiljö där de kan slappna av och vågar uttrycka sig, menar Saito \& Hayakawa Thor (2012: 214).

Deutschmann (2014) framhåller också vikten av att skapa en trygg och informell lärmiljö: "the creation of a 'low anxiety' environment where students would feel free to communicate using informal language" (2014: 90). Deutschmann, som undervisat i onlinekurser i engelska vid Mittuniversitetet i flera år, hävdar att det inte räcker med att förse studenterna med kursmaterial och instruktioner i en onlinekurs utan att man också måste skapa en kollaborativ lärmiljö. Han menar att det är viktigt att i början av en kurs skapa kontakt genom enkla och informella uppvärmningsövningar. Han ger ett exempel från sin egen undervisning i grammatik där studenterna får i uppgift att skriva en liten text om sina tidigare erfarenheter av grammatikstudier, och de uppmuntras då att berätta om anekdoter från skoltiden för varandra, t.ex. olika typer av lektioner och lärare som de har utsatts för. Detta påminner om "personalization", även om det i Deutschmanns fall handlar om ett skriftligt diskussionsforum. Enligt Deutschmann är dessa personliga texter ofta underhållande läsning och bidrar till att skapa en gruppkänsla. 
Cunningham, Beers Fägersten \& Holmsten (2010: 170) påpekar att möjligheten att tala muntligt med varandra i realtid under det nätbaserade seminariet bidrar till en känsla av närhet och kontakt mellan seminariedeltagarna. Deltagarnas röster innehåller paralingvistisk information, såsom känslor, tempo, sociogeografisk bakgrund, personlighet etc.

Kameran har flera viktiga funktioner att fylla. Kamerabilderna i våra seminarier fungerar synkront med ljudet, vilket gör att det går att se läpparna röra sig synkront med talet hos den som talar. Studenterna får därför stöd i lyssnandet genom läppläsning. Det är också möjligt att, åtminstone i viss mån, se talarens kroppsspråk. Enligt min erfarenhet syns tyvärr inte gester särskilt bra, men ansiktsyttryck, nickningar och liknande syns och bidrar till kommunikationen. Sådana små uttryck gör det lättare för den som talar att veta hur det som sägs tas emot av de andra seminariedeltagarna och om han eller hon gör sig förstådd. Det skapar också en känsla av social närvaro.

\subsection{Utmaningar och försvårande förutsättningar i nätbaserade synkrona seminarier}

Något som skiljer seminariet i det virtuella klassrummet från det traditionella klassrummets seminarium är ljudproblem. Dessa ljudproblem kan vara allt ifrån att studenten inte hörs över huvud taget till att ljudet är brusigt eller att studenten inte hör vad läraren eller de andra seminariedeltagarna säger. I ett sådant läge kan läraren och studenten kommunicera med varandra via den skriftliga chatten. Läraren kan t.ex. i chatten uppmana studenten att logga in i supportcaféet för att få hjälp med ljudet. Supportcaféet är ett samtalsrum där det finns teknisk personal tillgänglig som kan hjälpa till dagtid och långt in på kvällen.

Ett annat tekniskt problem som kan uppstå är att studenten på grund av dålig uppkoppling plötsligt kastas ut ur seminariet. Om deltagarna just då är uppdelade i olika grupprum hamnar studenten i det gemensamma huvudrummet när han eller hon sedan loggar in igen. Läraren är då tvungen att manuellt plocka in studenten i rätt grupprum vilket förstås är störande för både lärare och studenter.

Seminariedeltagande från bullriga miljöer kan också vara ett problem. Det händer någon gång att studenter försöker delta i seminarier från exempelvis internetcaféer, flygplatser eller tåg. Det är ofta högt bakgrundsljud, 
vilket naturligtvis kan störa andra kursdeltagare, och studenten ifråga kan själv känna sig hämmad att delta i seminariesamtalet med andra resenärer bredvid sig. De flesta deltar dock i seminarierna hemifrån, men störande inslag kan förekomma även i hemmiljön, såsom en dörrklocka som ringer, hundar som skäller, någon familjemedlem som slamrar med disken osv.

För att få bukt med dessa problem krävs det att läraren i början av kursen informerar om vikten av att ha bra teknisk utrustning och att se till att ha så lite bakgrundsljud som möjligt. Läraren måste ställa krav på studenterna. Om en student inte kan delta i samtalet för att ljudet inte fungerar bör studenten inte räknas som närvarande.

Cunningham, Beers Fägersten \& Holmsten (2010) beskriver kommunikationsproblem som kan uppstå vid nätbaserade onlineseminarier i engelska, men även strategier som studenter och lärare använder för att kompensera för dessa problem. Ett exempel på sådana kompenserande strategier är textchatten som ofta används som förstärkning och stöd till den muntliga kommunikationen på ett sätt som är unikt för den här typen av multimodalt klassrum. Som påpekas av Cunningham, Beers Fägersten \& Holmsten (2010: 166), behöver studenterna ibland hjälp med det tekniska under seminarier och då uppstår meta-modala samtal där läraren och ibland även studenter hjälper kursdeltagare med tekniken. Denna metakommunikation sker ofta i chattfönstret, både för att inte störa den egentliga aktiveten för mycket och för att de tekniska problemen ofta handlar om ljudproblem och då är chatten ibland den enda möjliga kommunikationskanalen. Nedan ges ett autentiskt exempel på detta från ett av mina seminarier i franska, muntlig språkfärdighet där studenter hjälper varandra med tekniken genom att skriva i chatten:

Student 1: Je n'entend rien...

Student 2: Reconnect

Student 3: Je crois qu'il faut appuyer aux "speakers"

Student 3: Il doit etre vert

I exemplet ser vi att en student har ljudproblem och inte hör något. En annan ger då rådet att logga in på nytt i samtalsrummet, vilket många gånger brukar lösa problemet. En tredje student misstänker att problemet beror på att studenten inte klickat igång ljudet. 
Cunningham, Beers Fägersten \& Holmsten (2010: 166) nämner att vissa studenter föredrar att kommunicera via chatten även om de inte har några ljudproblem. I våra seminarier i franska, muntlig språkfärdighet kan det i vissa sammanhang vara lämpligt att kommunicera skriftligt via chatten. Då är alla aktiva och skriver i chatten, och jag kan som lärare direkt uppmärksamma om någon inte hänger med. Exempelvis brukar vi göra en övning i helklass där studenterna ska svara på hur många stavelser olika ord och ordsekvenser innehåller och även ange om stavelserna är öppna (slutar på vokalljud) eller slutna (slutar på konsonantljud). Då får de skriva svaren i chatten. Ordet "phonétique" t.ex. innehåller tre stavelser varav de två första är öppna och den tredje är sluten, dvs. $\mathrm{OOF}$ (där $\mathrm{O}=$ ouverte och $\mathrm{F}=$ fermée). Sekvensen "c'est un ami" innehåller fyra stavelser som alla är öppna, dvs. OOOO. En sådan övning är lämplig att göra med hjälp av chatten, men i de flesta situationer brukar jag uppmana studenterna att prata istället för att skriva eftersom det är en kurs i muntlig språkfärdighet.

Chattfönstret kan även användas till att dela med sig av intressanta länkar. Det händer också att studenter i chatten ber läraren förklara något lite närmare. Ibland förekommer det att studenter skriver mindre viktiga, kanske skämtsamma kommentarer i chatten under pågånde muntligt samtal. Följande rader är också ett exempel på att studenter ibland rättar varandras inlägg:

Student 1: Est-ce que Stromae apporte les pantalons courts en hiver aussi?

Student 2: porte

Student 2: :)

I exemplet frågar student $1 \mathrm{om}$ artisten Stromae bär kortbyxor även på vintern. Student 2 , som anser att student 1 använt fel verb, skriver det rätta verbet och lägger därefter till en förmildrande smiley.

Chattverktyget kan alltså ses som en kompensation för de ljudproblem som kan uppstå vid nätbaserade onlineseminarier. I en kurs i muntlig språkfärdighet bör chatten självfallet användas med måtta, men i andra kurser kan den vara ett viktigt verktyg som tillför något extra jämfört med den enbart muntliga interaktionen i ett traditionellt seminarium.

Det förekommer att studenter deltar i seminariet utan att ha full koncentration på seminariet, exempelvis för att de samtidigt har ett barn närvarande, 
ett problem som också Högberg (2015: 170) tar upp. Studenten får då en försämrad uppmärksamhet som delvis är dold för de andra seminariedeltagarna. Här har kameran en viktig funktion att fylla. Med hjälp av kamerabilderna kan läraren bättre hålla koll på studenternas aktivitet. Om studenten fryser sin kamerabild, vilket är tekniskt möjligt, går det inte att vara säker på att han eller hon sitter kvar vid datorn. Det händer ibland att studenter inte svarar på tilltal och lite senare säger att de gick iväg för att hämta kaffe eller öppna dörren för någon som ringde på. Det finns en step away-funktion som seminariedeltagarna kan slå på ifall de tillfälligt måste lämna seminariet, men den används sällan. Ibland skriver studenterna i chatten att de måste gå iväg men snart kommer tillbaka. Som Cunningham, Beers Fägersten $\&$ Holmsten (2010: 169) nämner, är det extra viktigt att lärare kan bedöma studenternas aktiva deltagande vid seminarier som är betygsgrundande, vilket är fallet för våra seminarier i franska, muntlig språkfärdighet. Därför kräver vi i princip påslagna kameror under dessa seminarier, även om det undantagsvis kan hända att studenter av olika anledningar inte kan använda sin kamera vid något seminarium. Enligt Cunningham, Beers Fägersten \& Holmsten (2010: 169) är många studenter märkligt motvilliga till att använda webbkamera, något som enligt författarna skulle kunna bero på den anonymitet som man ofta förknippar med datorbaserad kommunikation. Jag upplever dock inte denna motvilja som så stor, även om jag ofta får be studenterna att slå på sina webbkameror i början av seminariet, alla gör det inte självmant. Om inte studenterna har sina kameror påslagna har man som lärare dessutom svårare att se om de hänger med, och man kan få en känsla av att tala ut i tomma intet utan att veta om någon hör eller förstår det man säger. Den återkoppling som kamerabilderna ger är därför viktig för att se om man har studenternas uppmärksamhet och om de hänger med. Cunningham, Beers Fägersten \& Holmsten (2010: 168-169) tar också upp denna aspekt och påpekar att vid avsaknad av webbkameror kompenserar många lärare för detta genom att ofta tilltala studenterna vid namn och be dem svara på frågor. 


\subsection{Att skapa en fungerande muntlig interaktion i det virtuella klassrummet}

I en studie av Saito, Pruth, Inose, Mizufune \& Hayakawa Thor (2012) om pedagogiska metoder i nätbaserad språkundervisning svarade 15 lärare på en enkät och 11 lärare intervjuades. Lärarna, som alla undervisade på nätbaserade språkkurser, delade med sig av många intressanta idéer och förslag på hur man kan skapa en framgångsrik nätbaserad språkundervisning. Framför allt framkom vikten av att ge enkel och tydlig information till studenterna så att de vet vad som förväntas av dem. Detta är också ett sätt att motivera studenterna. Om informationen är bristfällig eller svår att hitta är det lätt att tappa motivationen. Som Saito m.fl. (2012: 436) nämner, är många studenter ovana vid nätbaserad undervisning och har många frågor och funderingar, och vissa studenter kan känna sig osäkra på grund av bristande datorvana. Det är därför viktigt att ge så tydlig och enkel information som möjligt redan när studenterna söker till kursen och fortsatt under hela kursens gång. Något som också framkom som mycket viktigt i enkätsvaren och i intervjuerna med lärarna, och som vi redan har berört här, är att skapa en trevlig atmosfär och en gruppkänsla. Det fanns en aktiv strävan att få studenterna att känna sig bekväma i undervisningssituationen och att försöka överbrygga det faktum att kursdeltagarna befinner sig geografiskt långt från varandra och därigenom riskerar att känna sig ensamma och isolerade. Läraren har också en viktig roll att fylla när det gäller att göra ett reflekterat upplägg av inspelade föreläsningar och onlineseminarier så att den begränsade realtiden med studenterna används på bästa sätt. Vilket stoff lämpar sig bäst för de inspelade föreläsningarna respektive de synkrona seminarierna? Att fundera över vilken typ av färdigheter som studenterna kan uppnå genom olika verktyg och medel är följaktligen en viktig del av lärarens arbete vid nätbaserad undervisning.

Vi kan sammanfattningsvis konstatera att det trots diverse tekniska problem faktiskt fungerar att skapa muntlig interaktion i det virtuella klassrummet. När det gäller vår kurs i franska, muntlig språkfärdighet, kommer de allra flesta studenter väl förberedda och med högt engagemang till det nätbaserade seminariet och deltar aktivt i övningar och diskussioner. Eftersom de befinner sig på olika geografiska platser kan de tillföra mycket till samtalet genom sina olika erfarenheter. Även de studenter som klagar 
på tekniska problem i kursvärderingen, brukar trots allt vara nöjda med kursen. Påfallande många studenter brukar skriva i kursvärderingen att det bästa med kursen var diskussionerna med de andra studenterna under seminarierna. Det förefaller som om många studenter inte störs av eller reflekterar särskilt mycket över det speciella i att träffas virtuellt istället för fysiskt. Exempelvis gav en student följande kommentar i sin kursvärdering: "Trevliga kurskamrater och ett tillåtande klassrumsklimat där man får säga fel och hjälpa varandra”. Kommentaren tyder på att denna student upplevde god kontakt med de andra kursdeltagarna och också på att det virtuella samtalsrummet upplevdes som ett verkligt klassrum där förutsättningarna för lärande var goda.

Akademisk utbildning i romanska språk bedrivs idag i Sverige i såväl traditionella som virtuella klassrum. Olika faktorer ligger till grund för studenternas val av nätbaserad eller traditionell utbildning, och delvis olika pedagogiska metoder och arbetssätt är tillämpliga i det virtuella klassrummet jämfört med det traditionella, men det mesta är sig ändå likt och i slutändan har sannolikt inte typen av klassrum någon egentlig betydelse för själva lärandet eller möjligheterna att uppnå kursmålen.

\section{Bibliografi}

Barker, Daniel, 2013: Flipped classroom - det omvända arbetssättet. Stockholm: Natur \& Kultur.

Bian, Li, 2009: Application of Digital Technology in Open and Distance Education. International Conference on Networking and Digital Society I. 273-276.

Cunningham, Una, Beers Fägersten, Kristy \& Holmsten, Elin, 2010: "Can you hear me, Hanoi?" Compensatory Mechanisms Employed in Synchronous Net-Based English Language Learning. International Review of Research in Open and Distance Learning vol. $11 \mathrm{nr}$ 1. 161-177.

Deutschmann, Mats, 2014: Creating Online Community: Challenges and Solutions. I: Sullivan, Kirk P. H., Czigler, Peter E. \& Sullivan Hellgren, Jenny M. (red.), Cases on Professional Distance Education Degree Programs and Practices: Successes, Challenges, and Issues. Hershey: IGI Global. 86-111.

Högberg, Sören, 2015: Om lärarskapets moraliska dimension - ett perspektiv och en studie av lärarstuderandes nätbaserade seminariesamtal. Örebro: Örebro University. 
Kawaguchi, Yoshikazu, 2004: Hyougenkyouiku to bunpoushidou no yuugou, "hatarakikakeru hyougen" to "kataru hyougen" kara mita shokyuubunpou. Journal CAJLE vol. 6. 57-70.

Messina Dahlberg, Giulia, 2015: Languaging in virtual learning sites - Studies of online encounters in the language-focused classroom. Örebro: Örebro University.

Saito, Rieko \& Hayakawa Thor, Masako, 2012: How to make active interactions in Japanese as a second language. International Conference of ICT for Language Learning. 211-214.

Saito, Rieko, Pruth, Alex, Inose, Hiroko, Mizufune, Yoko \& Hayakawa Thor, Masako, 2012: Pedagogical Methods in Web-Based Language TeachingMapping. International Conference of ICT for Language Learning. 433-437.

Säljö, Roger, 2000: Lärande i praktiken. Ett sociokulturellt perspektiv. Stockholm: Norstedts akademiska förlag.

Vygostky, Lev Semjonovitj, 1978: Mind in society: The development of higher psychological processes. Cambridge, MA: Harvard University Press. 